\title{
Those Left Behind From Voluntary Medical Home Reforms in Ontario, Canada
}

\author{
Tara Kiran, MD, MSc, CCFP ${ }^{1-3}$ \\ Alexander Kopp, BA ${ }^{3}$ \\ Richard H. Glazier, MD, MPH, \\ CCFP ${ }^{1-5}$
}

'Department of Family and Community Medicine, St Michael's Hospital, University of Toronto, Toronto, Canada

${ }^{2}$ Centre for Urban Health Solutions, Li Ka Shing Knowledge Institute of St Michael's Hospital, Toronto, Canada

${ }^{3}$ Institute for Clinical Evaluative Sciences, Toronto, Canada

${ }^{4}$ Dalla Lana School of Public Health, University of Toronto, Toronto, Canada

${ }^{5}$ Institute for Health Policy, Management and Evaluation, University of Toronto,

Toronto, Canada

Conflicts of interest: authors report none.

\section{CORRESPONDING AUTHOR}

Tara Kiran, MD, MSc, CCFP

30 Bond St

Toronto, Ontario, Canada M5B 1W8

tara.kiran@utoronto.ca

\begin{abstract}
PURPOSE Health systems are transitioning patients to medical homes to improve health outcomes and reduce cost. We sought to understand the characteristics and quality of care for patients who did and did not participate in the voluntary transition to medical homes.
\end{abstract}

METHODS We used administrative data for diabetes monitoring and cancer screening to compare services received by patients attached to a medical home $(n=10,785,687)$ with services received by those seeing a fee-for-service physician $(n=1,321,800)$ in Ontario, Canada, on March 31, 2011. We used Poisson regression to examine associations in 2011 after adjustment for patient factors and also assessed changes in outcomes between 2001 and 2011.

RESULTS Patients attached to a fee-for-service physician were more likely to be immigrants and live in a low-income neighborhood and urban area. They were less likely to receive recommended testing for diabetes (25\% vs $34 \%$; adjusted relative risk $[R R]=0.74 ; 95 \%(\mathrm{Cl}, 0.73-0.75)$ and less likely to receive screening for cervical ( $52 \%$ vs $66 \%$; adjusted RR $=0.79 ; 95 \% \mathrm{Cl}, 0.79-0.79)$, breast $(58 \%$ vs $73 \%$; adjusted $\mathrm{RR}=0.80 ; 95 \% \mathrm{Cl}, 0.80-0.81)$, and colorectal cancer (44\% vs $62 \%$; adjusted $\mathrm{RR}=0.72 ; 95 \% \mathrm{Cl}, 0.71-0.72$ ) compared with patients attached to a medical home physician in 2011 . These differences in quality of care preceded medical home reforms.

CONCLUSION Patients left behind from medical home reforms are more likely to be poor, urban, and new immigrants and receive lower quality care. Strategies are needed to reach out to these patients and their physicians to reduce gaps in care.

Ann Fam Med 2016;14:517-525. doi: 10.1370/afm.2000.

\section{INTRODUCTION}

H ealth systems with strong primary care have better outcomes, lower costs, and fewer disparities. ${ }^{1}$ Widespread implementation of the medical home is seen as a promising way to improve primary care. ${ }^{2-5}$ In a medical home, practices provide care to a population of patients using a multidisciplinary team approach. Other core features include enhanced access for patients, care coordination, and a focus on quality and safety. ${ }^{6}$ Payment reform is an essential element of a medical home and requires shifting physicians from fee-for-service remuneration to capitation or blended payments. ${ }^{78}$ Early evidence suggests that medical homes have the potential to improve the quality of chronic disease prevention and management ${ }^{9-12}$ and reduce medical utilization..$^{11-13}$

During the last decade, more than three-quarters of family physicians in Ontario, Canada, have transitioned from a traditional fee-for-service practice to a medical home that incorporates blended capitation payment and, in some cases, funding for nonphysician health professionals. ${ }^{14}$ Transitioning to a medical home was voluntary for both physicians and their patients. Remuneration in a medical home was generally higher than in fee-for-service practice, so physicians had a financial incentive to join. ${ }^{15}$ In contrast to traditional fee-for-service, where physicians ran independent offices akin to small businesses, most medical homes required physicians to organize into groups, 
although colocation was not a requirement. Medical home obligations included formal patient enrollment and provision of after-hours care. Post-hoc evaluations have found differences in quality of care related to the type of physician payment in a medical home, ${ }_{1}^{16,17}$ as well as lower rates of diabetes monitoring in patients not enrolled to a medical home. ${ }^{16}$ Still, little is known about the physicians who have opted not to join a medical home and the characteristics and quality of care of patients who do not have a medical home physician.

We assessed the characteristics of patients and physicians who did and did not participate in the voluntary transition to medical home models in Ontario. We compared the quality of care for patients attached to a medical home with those attached a traditional fee-forservice physician and assessed whether differences in care preceded introduction of the reforms.

\section{METHODS}

\section{Setting}

Ontario is Canada's largest province with a population of approximately 13.7 million in 2014. All permanent residents are covered by the Ontario Health Insurance Plan, and physician visits and medically necessary laboratory tests are free at the point-of-care.

Medical homes were introduced in Ontario in 2002. ${ }^{14}$ Physicians have the option of choosing among different medical home models. All models strongly encourage physicians to enroll patients, and all require physicians to provide after-hours care. In all models, a portion of physician remuneration is by capitation, with the amount ranging from $20 \%$ to $80 \%$ depending on the model. Capitation payments are adjusted for age and sex but not for comorbidity or deprivation. Medical home physicians are also eligible for financial incentives related to chronic disease management and preventive care, and 1 medical home model is eligible for funding to hire other health professionals.

\section{Population and Study Design}

We stratified all Ontario residents by whether their primary care physician was practicing in a medical home as of March 31, 2011 and conducted a retrospective analysis to 2001 to examine quality of care over time. Specifically, we assessed whether they were eligible for and received recommended testing for diabetes and screening for cervical, breast, and colorectal cancer for each year between 2001 and 2011. Patients were excluded if they were registered to a Community Health Centre $(1.0 \%, \mathrm{n}=139,274)$ because we did not have access to complete billing data.

We used population-based administrative data claims accessed through a comprehensive research agreement between the Institute for Clinical Evaluative Sciences (ICES) and the Ontario Ministry of Health and Long-Term Care. Data were linked using unique, encoded identifiers and analyzed at ICES. This study was approved by the Research Ethics Board of Sunnybrook Health Sciences Centre in Toronto, Ontario.

\section{Physician Practices}

We included physicians who qualified in a specialty that typically provides primary care in Ontario, specifically general practitioners, family physicians, pediatricians, and community medicine specialists. General internal medicine specialists were not included, as they do not provide primary care in our setting. Some pediatricians provide primary care in Ontario, so we incorporated them for completeness; pediatricians, however, were not included in the reforms that are the focus of this article. We used enrollment tables provided by the Ontario Ministry of Health and Long-Term Care to assign a primary care physician to Ontario residents who were formally enrolled in a medical home. The remaining residents were assigned to the primary care physician who billed the maximum value of $23 \mathrm{com}$ monly billed primary care codes in a 2-year period (Supplemental Appendix Table 1, http://www.annfammed.org/content/14/6/517/suppl/DC1).

Physicians not in a medical home were categorized as either comprehensive fee-for-service or noncomprehensive-fee-for-service. Comprehensive fee-for-service physicians received $50 \%$ or more of their payments from core primary care services, had billings in at least 7 activity areas, and worked at least 1 day a week (Supplemental Appendix Table 2, http://www.annfammed. org/content/14/6/517/suppl/DC1).

The remaining physicians were categorized as noncomprehensive fee-for-service physicians and included those with a focused practice designation (eg, emergency medicine, hospitalist, general practice psychotherapy), some of whom continue to see patients in an outpatient primary care setting.

\section{Quality of Care}

We assessed whether patients with diabetes received recommended testing and whether eligible patients received screening for cervical, breast, and colorectal cancer. Ontarians aged 40 years and older who had diabetes were identified by using a validated algorithm that had an $86 \%$ sensitivity and $97 \%$ specificity. ${ }^{18}$ By using claims for laboratory, physician, and optometrist services, we were able to assess whether Ontarians with diabetes received the following recommended testing according to the Canadian Diabetes Association 2008 Clinical Practice Guidelines: 4 hemoglobin $\mathrm{A}_{1 \mathrm{C}}$ tests, 1 cholesterol test, and 1 eye examination in 
a 2-year period. ${ }^{19}$ We used laboratory and physician service claims, together with the provincial cancer registry, to assess eligibility and receipt of cancer screening ${ }^{20}$ (Supplemental Appendix Table 3, http://www. annfammed.org/content/14/6/517/supp1/DC1).

\section{Other Data Sources}

Using the provincial registry, we obtained residents' age, sex, and postal codes, and by linking patient postal codes to census data, we were able to derive neighborhood income quintile. Rurality was calculated using the Rurality Index of Ontario (0-9= major urban, 10-39 = nonmajor urban, $\geq 40=$ rural) ${ }^{21}$ The Citizenship and Immigration Canada database allowed us to look for residents who immigrated within the past 10 years and settled in Ontario upon arrival. We also looked at Ontario Health Insurance Plan (OHIP) registration within the past 10 years to capture interprovincial migrants, some of whom might have been immigrants. We then used the Johns Hopkins Adjusted Clinical Groups software to capture comorbidity ( $1=$ low comorbitidy, 5 = high comorbidity) according to Aggregated Diagnosis Groups and to assign patients to Resource Utilization Bands based on similar expected health care utilization $(1=$ low, $5=$ high $) .{ }^{22}$ Physician characteristics were obtained from physician databases held at ICES. Finally, we used previously validated algorithms based on physician billings and hospital discharge databases to select patients with specific chronic diseases (acute myocardial infarction, congestive heart failure, hypertension, chronic obstructive pulmonary disease, asthma, mental illness, diabetes mellitus). ${ }^{18,23-28}$

\section{Analysis}

We used Poisson regression models to compare rates of recommended testing for diabetes and cancer screening in 2011 between patients attached to a medical home and those attached to a traditional fee-forservice physician because the outcomes were relatively common, and we wanted to express the results in terms of relative risk. ${ }^{29}$ After adjusting for patient demographics (age, neighborhood income quintile, immigration, and rurality) and patient comorbidity (presence of the specific chronic diseases listed above and Resource Utilization Band), we used generalized estimating equations to account for correlations between patients attached to the same physician and physicians belonging to the same group. ${ }^{30}$ Most medical home models require physicians to be organized in groups for administration and after-hours care. ${ }^{14}$

We followed patients back to 2001, before reforms were introduced, to determine whether differences noted in 2011 predated a transition to a medical home. We then assessed eligibility and receipt of recommended testing and screening in each year between 2001 and 2011. In our primary analysis, we excluded residents whose last contact with the health system was more than 6 years ago. We also conducted a sensitivity analysis excluding residents whose last contact with the health system was more than 2 years ago.

\section{RESULTS}

In 2011 there were 13,161,935 permanent Ontario residents covered by the Ontario health insurance plan, $2,376,248(18 \%)$ of whom who were not attached to a medical home (Table 1). Compared with Ontarians attached to a medical home, patients attached to a comprehensive fee-for-service physician ( $\mathrm{n}=771,471$, $6 \%$ ) were more likely to reside in a lower income neighborhood, live in an urban area, and have immigrated in the last 10 years. Patients attached to a noncomprehensive fee-for-service physician ( $\mathrm{n}=550,329$, $4 \%$ ) were more likely to be younger than 19 years, live in an urban area, and not have hypertension and diabetes. There were 1,054,448 (8\%) Ontarians who had no primary care visit in the last 2 years, and these residents were more likely to be male, be between the ages of 19 and 44 years, live in a low-income neighborhood, have immigrated in the last 10 years, and have low comorbidity and morbidity.

There were 5,059 Ontario primary care physicians $(41 \%$ of 12,253$)$ that did not practice in a medical home in 2011. Physicians practicing comprehensive fee-for-service $(\mathrm{n}=1,229,10 \%)$ and noncomprehensive fee-for-service ( $n=3,830,31 \%)$ were more likely to be international medical graduates and be either younger than 40 years or aged 65 years and older compared with physicians practicing in a medical home (Table 2). Panel sizes were relatively small with most physicians having fewer than 650 patients. Nearly all comprehensive fee-for-service physicians and medical home physicians practiced as general practitioners or family physicians; $70 \%$ of noncomprehensive fee-forservice physicians were general practitioners or family physicians, and the remainder were mostly pediatricians (results not shown).

Compared with patients attached to a medical home physician in 2011, patients attached to a comprehensive fee-for-service physician were less likely to receive recommended testing for diabetes ( $25 \%$ vs $34 \%$; adjusted relative risk $[\mathrm{RR}]=0.74 ; 95 \% \mathrm{CI}, 0.73-0.75)$ and less likely to receive screening for cervical $(52 \%$ vs $66 \%$; adjusted $\mathrm{RR}=0.79 ; 95 \% \mathrm{CI}, 0.79-0.79)$, breast (58\% vs $73 \%$; adjusted $\mathrm{RR}=0.80 ; 95 \% \mathrm{CI}, 0.80-0.81$ ), and colorectal cancer $(44 \%$ vs $62 \%$; adjusted $\mathrm{RR}=0.72$; 95\% CI, 0.71-0.72) (Table 3). Findings were similar for patients attached to noncomprehensive fee-for-service 
physicians. Patients who had no primary care visit had very low rates of recommended testing for diabetes (7\%) and screening for cervical (8\%), breast (11\%), and colorectal cancer (12\%) (results not shown).
Figure 1 depicts diabetes testing and cancer screening rates for eligible patients over time with corresponding confidence intervals. Differences in quality of care between patients attached to fee-for-service

Table 1. Characteristics of Patients Attached to Physicians Not Practicing in a Medical Home Compared With Those Attached to a Medical Home Physician, March 31, 2011

\begin{tabular}{|c|c|c|c|c|c|}
\hline \multirow[b]{2}{*}{ Characteristic } & \multicolumn{3}{|c|}{ Patients Left Behind From Medical Home Reforms } & \multirow{2}{*}{$\begin{array}{l}\text { Patients } \\
\text { Attached to } \\
\text { a Medical } \\
\text { Home }\end{array}$} & \multirow[b]{2}{*}{$\begin{array}{c}\text { All } \\
\text { Ontarians }\end{array}$} \\
\hline & $\begin{array}{c}\text { No Primary Care } \\
\text { Physician Visit in } \\
\text { Past } 2 \text { Years }\end{array}$ & $\begin{array}{c}\text { Noncomprehensive } \\
\text { Fee-for-Service } \\
\text { Physician }\end{array}$ & $\begin{array}{c}\text { Comprehensive } \\
\text { Fee-for-Service } \\
\text { Physician }^{\mathrm{a}}\end{array}$ & & \\
\hline Number of patients & $1,054,448$ & 550,329 & 771,471 & $10,785,687$ & $13,161,935$ \\
\hline Male, No. (\%) & $656,710(62)$ & $286,997(52)$ & $397,770(51)$ & $5,125,358(48)$ & $6,466,459(49)$ \\
\hline$<19$ y & $232,239(22)$ & $283,970(52)$ & $166,776(22)$ & $2,230,356(21)$ & $2,913,341(22)$ \\
\hline $19-44$ y & $494,016(47)$ & $135,814(25)$ & $297,521(39)$ & $3,719,174(34)$ & $4,646,525(35)$ \\
\hline $45-64 y$ & $247,697(24)$ & $86,032(16)$ & $208,895(27)$ & $3,192,778(30)$ & $3,735,402(28)$ \\
\hline$\geq 65 y$ & $80,496(8)$ & $44,513(8)$ & $98,279(13)$ & $1,643,379(15)$ & $1,866,667$ (14) \\
\hline \multicolumn{6}{|l|}{ Income quintile, No. (\%) } \\
\hline Quintile 1 (low) & $258,599(25)$ & $111,222(20)$ & $180,884(24)$ & $1,934,979(18)$ & $2,485,684(19)$ \\
\hline Quintile 3 & $191,687(18)$ & $100,145(18)$ & $154,164(20)$ & $2,178,988(20)$ & $2,624,984(20)$ \\
\hline Quintile 4 & $189,541(18)$ & $112,437(20)$ & $144,285(19)$ & $2,326,973(22)$ & $2,773,236(20)$ \\
\hline Quintile 5 (high) & $192,037(18)$ & $121,154(22)$ & $120,968(16)$ & $2,234,612(21)$ & $2,668,771(20)$ \\
\hline Missing data & $10,295(1)$ & $4,319(1)$ & $3,148(<1)$ & $34,135(<1)$ & $51,897(<1)$ \\
\hline \multicolumn{6}{|l|}{ Immigration, No. (\%) } \\
\hline Immigrated in past $10 \mathrm{y}$ & $101,520(10)$ & $29,100(5)$ & $85,024(11)$ & $704,975(7)$ & $920,619(7)$ \\
\hline Other newcomer in past $10 \mathrm{y}$ & $96,072(9)$ & $17,730(3)$ & $37,621(5)$ & $302,996(3)$ & $454,419(3)$ \\
\hline Long-term resident & $856,856(81)$ & $503,499(92)$ & $648,826(84)$ & $9,777,716(91)$ & $11,786,897$ (90) \\
\hline \multicolumn{6}{|l|}{ Rurality index, No. (\%) } \\
\hline Major urban & $746,503(71)$ & $438,036(80)$ & $643,812(84)$ & $7,716,288(72)$ & $9,544,639(73)$ \\
\hline Nonmajor urban & $178,345(17)$ & $72,985(13)$ & $83,451(11)$ & $2,197,486(20)$ & $2,532,267$ (19) \\
\hline Rural & $101,439(10)$ & $30,984(6)$ & $40,436(5)$ & $800,973(7)$ & $978,832(7)$ \\
\hline Missing data & 28,161 (3) & $8,324(2)$ & $3,772(1)$ & $70,940(1)$ & $111,197(1)$ \\
\hline \multicolumn{6}{|l|}{ ADG, No. (\%) } \\
\hline No utilization & $759,650(72)$ & $7,573(1)$ & $2,109(0.3)$ & $535,415(5)$ & $1,304,747$ (10) \\
\hline 1-4 (low comorbidity) & $266,013(25)$ & $297,807(54)$ & $412,041(53)$ & $5,093,469(47)$ & $6,069,330(46)$ \\
\hline $5-9$ & $25,599(2)$ & $208,188(38)$ & $298,763(39)$ & $4,241,021$ (39) & $4,773,571(36)$ \\
\hline$>10$ (high comorbidity) & $3,186(<1)$ & $36,761(7)$ & $58,558(8)$ & $915,782(8)$ & $1,014,287(8)$ \\
\hline \multicolumn{6}{|l|}{ Chronic disease prevalence, No. (\%) } \\
\hline Hypertension & $68,855(7)$ & $64,829(12)$ & $149,588(19)$ & $2,406,287(22)$ & $2,690,300(20)$ \\
\hline Congestive heart failure & $7,381(1)$ & $6,714(1)$ & $10,878(1)$ & $196,300(2)$ & $221,121(2)$ \\
\hline Acute myocardial infarction & $4,112(<1)$ & $3,907(1)$ & $7,560(1)$ & $132,664(1)$ & $148,730(1)$ \\
\hline COPD & $22,249(2)$ & $21,518(4)$ & $38,882(5)$ & $660,084(6)$ & $743,649(6)$ \\
\hline Asthma & $88,574(8)$ & $94,602(17)$ & $106,000(14)$ & $1,569,317(15)$ & $1,858,465(14)$ \\
\hline Mental illness & $19,613(2)$ & $93,776(17)$ & $158,383(21)$ & $2,253,130(21)$ & $2,524,459(19)$ \\
\hline Diabetes and age $>40$ y & $26,822(3)$ & $25,888(5)$ & $60,549(8)$ & $952,721(9)$ & $1,065,721(8)$ \\
\hline \multicolumn{6}{|l|}{$\begin{array}{l}\text { Eligible for cancer screening, } \\
\text { No. (\%) }\end{array}$} \\
\hline Cervical cancer & $134,717(12.8)$ & $54,166(10)$ & $136,071(18)$ & $2,240,498(21)$ & $2,565,452(20)$ \\
\hline Breast cancer & $55,890(5)$ & $27,053(5)$ & $67,099(9)$ & $1,126,105(10)$ & $1,276,147(10)$ \\
\hline Colorectal cancer & $172,997(16)$ & $72,317(13)$ & $175,023(23)$ & $2,741,778(25)$ & $3,162,115(24)$ \\
\hline
\end{tabular}

ADG = Aggregated Diagnosis Group; COPD = chronic obstructive pulmonary disease

a Comprehensive primary care indicates working at least 1 day per week, more than $50 \%$ of services or payments are for core primary care, and had billings in 7 or more activity areas. 
Table 2. Characteristics of Primary Care Physicians Not Practicing in a Medical Home Compared With Those Practicing in a Medical Home, March 31, 2011

\begin{tabular}{|c|c|c|c|c|}
\hline \multirow[b]{2}{*}{ Characteristic } & \multicolumn{2}{|c|}{$\begin{array}{l}\text { Physicians Left Behind From } \\
\text { Medical Home Reforms }\end{array}$} & \multirow[b]{2}{*}{$\begin{array}{l}\text { Physicians } \\
\text { Practicing in a } \\
\text { Medical Home }\end{array}$} & \multirow[b]{2}{*}{$\begin{array}{l}\text { All Ontario } \\
\text { Primary Care } \\
\text { Physicians }\end{array}$} \\
\hline & $\begin{array}{l}\text { Noncomprehensive } \\
\text { Fee-for-Service } \\
\text { Physician }\end{array}$ & $\begin{array}{c}\text { Comprehensive } \\
\text { Fee-for-Service } \\
\text { Physician }^{\mathrm{a}}\end{array}$ & & \\
\hline Overall, No. & 3,830 & 1,229 & 7,193 & 12,253 \\
\hline Male, No. (\%) & $2,262(59)$ & $717(58)$ & $4,244(59)$ & $7,223(59)$ \\
\hline Missing data & $105(3)$ & $0(0)$ & $\leq 5(<1)$ & $110(1)$ \\
\hline \multicolumn{5}{|l|}{ Age-group, No. (\%) } \\
\hline$<40 y$ & $912(24)$ & $277(23)$ & $1,199(17)$ & $2,388(20)$ \\
\hline $40-64, y$ & $2,117(55)$ & $666(54)$ & $5,208(72)$ & $7,991(65)$ \\
\hline$\geq 65, y$ & $606(16)$ & $283(23)$ & $781(11)$ & $1,670(14)$ \\
\hline Missing data & $195(5)$ & $\leq 5(<1)$ & $\leq 5(<1)$ & $204(2)$ \\
\hline Canadian medical graduate, No. (\%) & $2,754(72)$ & $814(66)$ & $5,376(75)$ & $8,944(73)$ \\
\hline Missing data & $195(5)$ & $\leq 5(<1)$ & $\leq 5(<1)$ & $204(2)$ \\
\hline Panel size, median (IQR) & $28(5-118)$ & $394(132-872)$ & $1,403(962-1,938)$ & $879(100-1,584)$ \\
\hline \multicolumn{5}{|l|}{ Panel size, No. (\%) } \\
\hline $0-649$ & $3,605(94)$ & $802(65)$ & $783(11)$ & $5,190(42)$ \\
\hline $650-999$ & $104(3)$ & $163(13)$ & $1,176(16)$ & $1,443(12)$ \\
\hline $1,000-1,499$ & $69(2)$ & $137(11)$ & $2,017(28)$ & $2,223(18)$ \\
\hline $1,500-1,999$ & $32(1)$ & $69(6)$ & $1,568(22)$ & $1,669(14)$ \\
\hline $2,000-2,399$ & $7(<1)$ & $20(2)$ & $815(11)$ & $842(7)$ \\
\hline$\geq 2,400$ & $13(<1)$ & $38(3)$ & $834(12)$ & $886(7)$ \\
\hline
\end{tabular}

$\mathrm{IQR}=$ interquartile range.

a Comprehensive primary care indicates working at least 1 day per week, more than $50 \%$ of services or payments are for core primary care, and had billings in 7 or more activity areas.

Table 3. Quality of Care for Those Left Behind From Medical Home Reforms Compared With Those Attached to a Medical Home, March 31, 2011

\begin{tabular}{|c|c|c|c|}
\hline Quality of Care Measure & $\begin{array}{l}\text { Crude Rate } \\
\% \text { (No.) }\end{array}$ & $\begin{array}{l}\text { Unadjusted RR } \\
\qquad(95 \% \mathrm{Cl})\end{array}$ & $\begin{array}{l}\text { RR Adjusted for Patient } \\
\text { Demographics }{ }^{b} \text { and } \\
\text { Comorbidity }^{c}(95 \% \mathrm{Cl})\end{array}$ \\
\hline \multicolumn{4}{|l|}{ Recommended testing for diabetes } \\
\hline Comprehensive fee for service & $25(12,799)$ & $0.74(0.72-0.75)$ & $0.74(0.73-0.75)$ \\
\hline Noncomprehensive fee for service & $23(5,022)$ & $0.68(0.66-0.69)$ & $0.68(0.67-0.70)$ \\
\hline \multicolumn{4}{|l|}{ Cervical cancer screening } \\
\hline Comprehensive fee for service & $52(67,963)$ & $0.78(0.77-0.78)$ & $0.79(0.79-0.79)$ \\
\hline Noncomprehensive fee for service & $50(26,096)$ & $0.75(0.74-0.75)$ & $0.76(0.75-0.76)$ \\
\hline Attached to a medical home & $66(1,460,364)$ & 1 [Reference] & 1 [Reference] \\
\hline \multicolumn{4}{|l|}{ Breast cancer screening } \\
\hline Comprehensive fee for service & $58(38,078)$ & $0.79(0.78-0.79)$ & $0.80(0.80-0.81)$ \\
\hline Attached to a medical home & $73(815,225)$ & 1 [Reference] & 1 [Reference] \\
\hline \multicolumn{4}{|l|}{ Colorectal cancer screening } \\
\hline Comprehensive fee for service & $44(74,929)$ & $0.70(0.70-0.71)$ & $0.72(0.71-0.72)$ \\
\hline Noncomprehensive fee for service & $45(31,831)$ & $0.72(0.72-0.73)$ & $0.73(0.72-0.74)$ \\
\hline Attached to a medical home & $62(1,673,652)$ & 1 [Reference] & 1 [Reference] \\
\hline \multicolumn{4}{|l|}{$\mathrm{RR}=$ relative risk } \\
\hline \multicolumn{3}{|c|}{$\begin{array}{l}\text { 'Adjustment for the following patient comorbidities: acute myocardial infarction, congestive heart failure, hypertension, chronic obstructive pulmonary disease, } \\
\text { asthma, mental illness, diabetes mellitus (excluded when assessing recommended testing for diabetes), Resource Utilization Band. }\end{array}$} & $\begin{array}{l}\text { hronic obstructive pulmonary disease } \\
\text { Band. }\end{array}$ \\
\hline
\end{tabular}


physicians and medical home physicians were present in 2001, before medical home reforms, with no overlap in the confidence intervals between the 2 groups. The absolute difference in diabetes testing and cancer screening for patients attached to a medical home vs those not attached to a medical home was greater in 2011 than in 2001. Patterns were similar in the sensitivity analysis where we excluded patients whose last contact with the health system was greater than 2 years (vs 6 years) (results not shown).

\section{DISCUSSION}

We found that approximately 1 in 6 Ontarians were left behind from medical home reforms almost a decade after their introduction. Patients left behind were less likely to receive recommended chronic disease management and prevention than patients who were attached to a medical home. These differences in quality of care preceded introduction of medical home reforms, and gaps in care have widened with time. Patients seeing comprehensive feefor-service physicians were more likely to come from poor neighborhoods, live in urban areas, and have immigrated in the last 10 years compared with patients in medical home models. Comprehensive and noncomprehensive fee-for-service physicians were more likely to be older, be international medical graduates, and have smaller panel sizes.

Joining a medical home in Ontario was voluntary for both physicians and patients, but most patients joined when their existing physician chose to enter a medical home model. Because relatively few family physicians have been unconditionally accepting new patients during the last decade, ${ }^{31,32}$ patients without an existing family physician would have found it challenging to sign up with a medical home physician; likewise, it would
Figure 1A-B. Percentage of patients receiving chronic disease management and prevention between 2001 and 2011 stratified by whether patient is attached to a medical home or a fee-for-service physician in 2011.

A. Recommended testing for diabetes

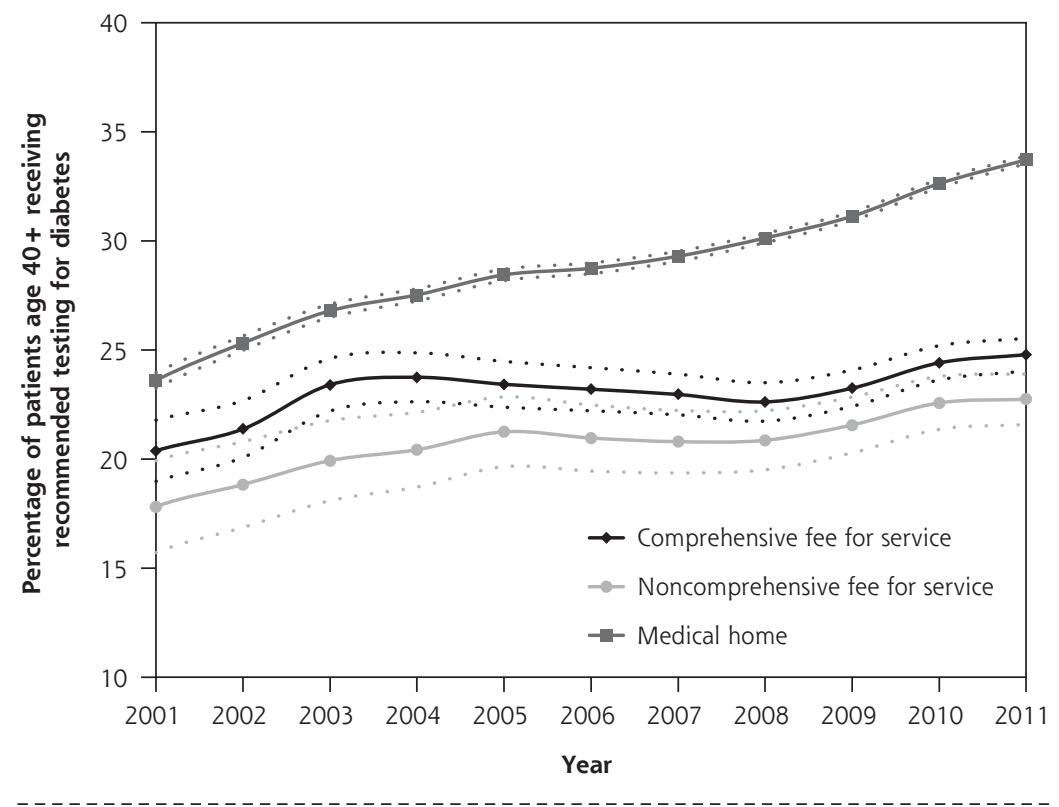

B. Cervical cancer screening

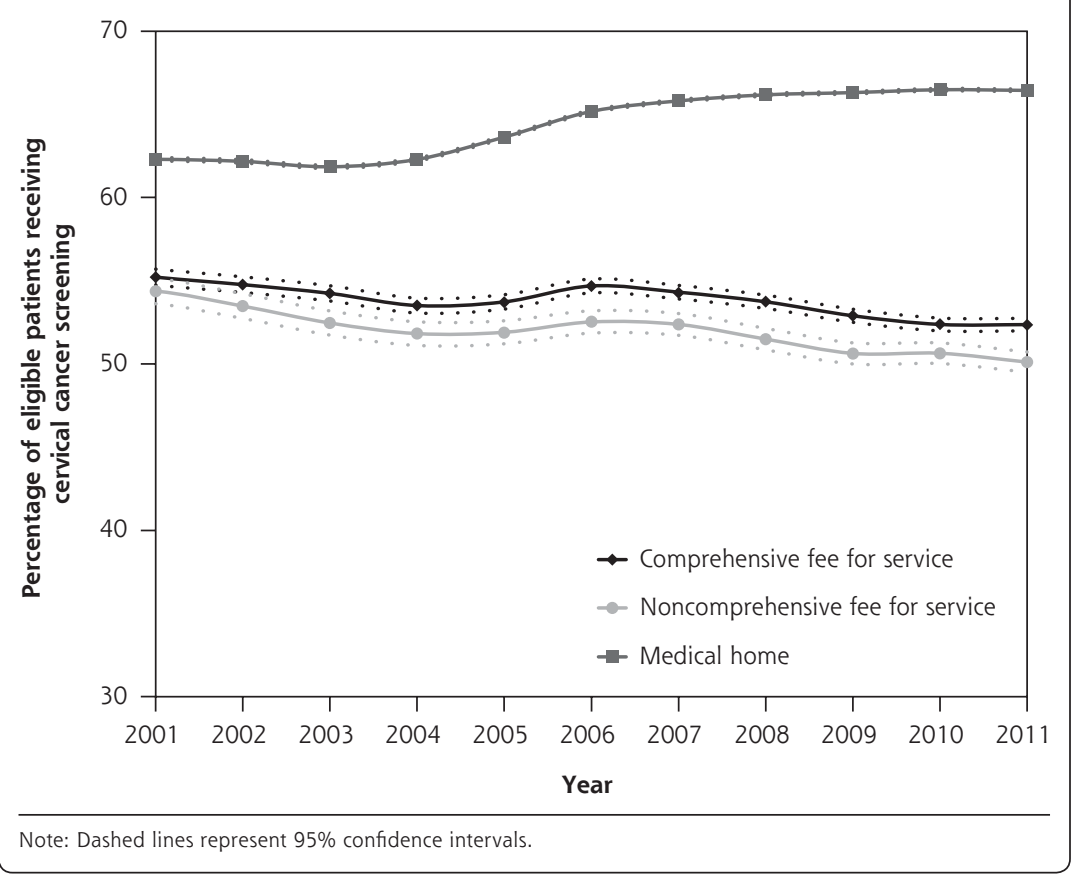

have been difficult for patients to switch to a physician in a medical home. Geographic access to medical home models may have influenced the characteristics of patients left behind. For example, there are fewer medical home models ${ }^{33}$ and more walk-in clinics ${ }^{32}$ in urban 


\section{Figure 1C-D. Percentage of patients receiving chronic disease management and prevention between 2001 and 2011 stratified by whether patient is attached to a medical home or a fee-for-service physician in 2011.}

C. Breast cancer screening

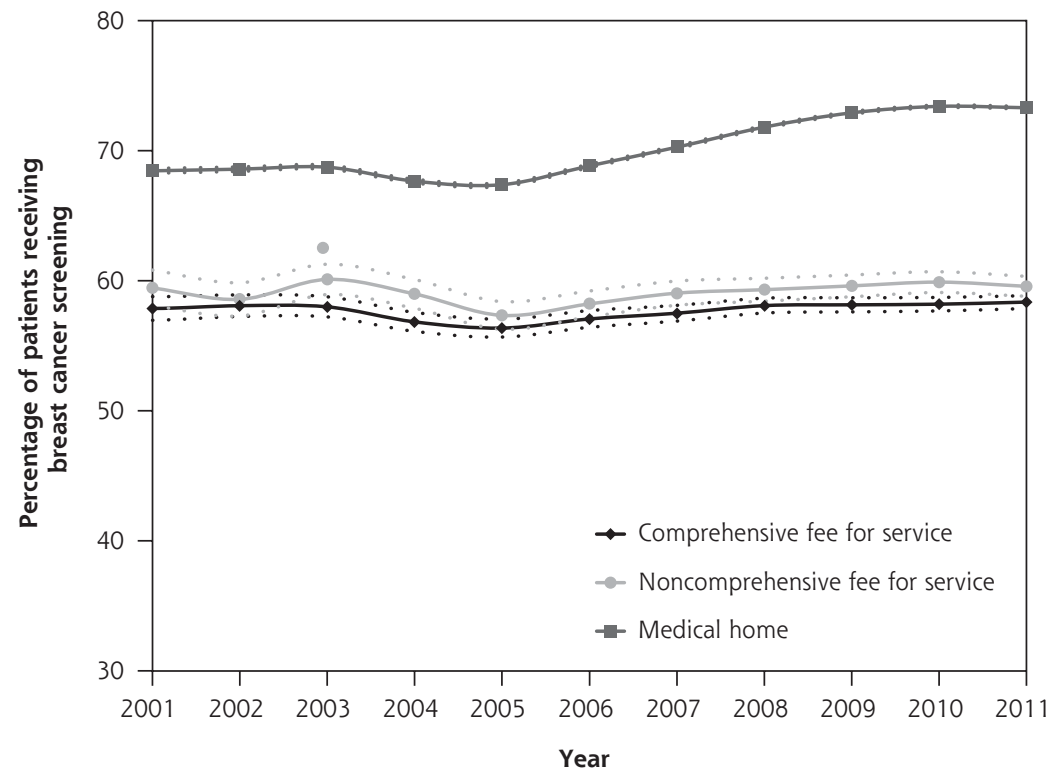

D. Colorectal cancer screening

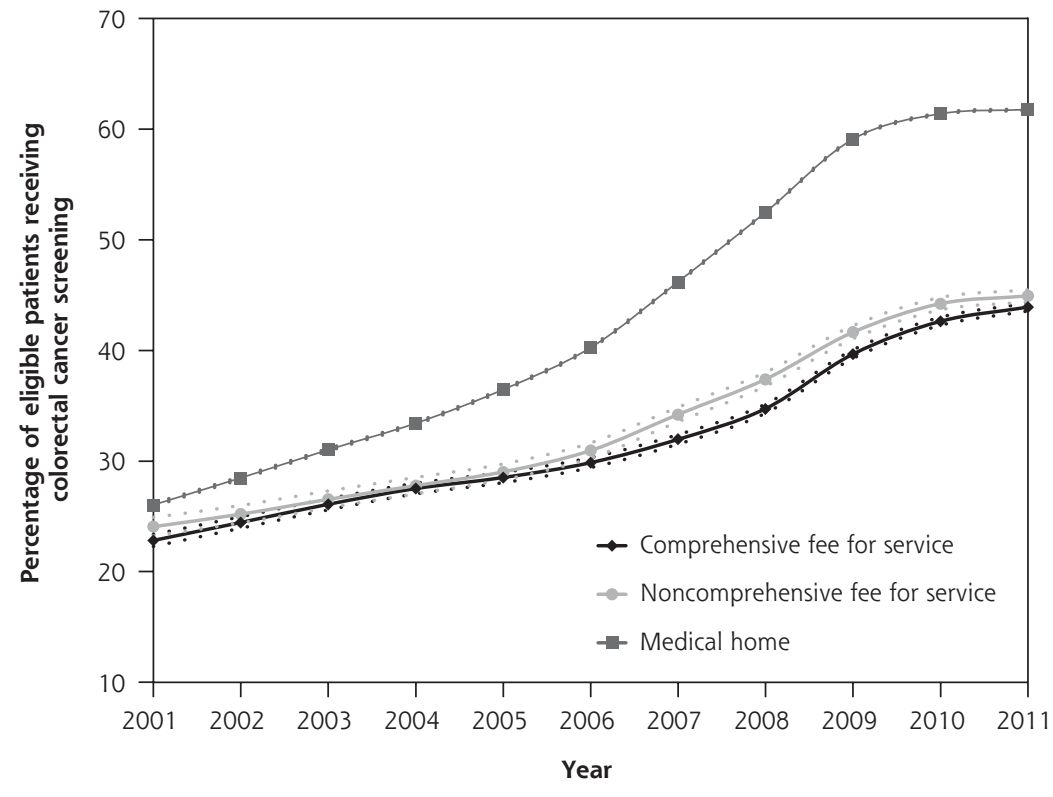

Note: Dashed lines represent 95\% confidence intervals. tence of the inverse care $\operatorname{law}^{35}$ in Ontario, despite sizeable investments in primary care reforms.

We found that patients whose physicians did not join a medical home were less likely to receive recommended testing even before medical home reforms. Many of these patients did not have a primary care visit in the last 2 years. Although a portion of those without a primary care visit were probably healthy young adults, it was likely they could not find a family physician. Some of the patients left behind were seeing physicians in a fee-for-service practice. These fee-for-service physicians were more likely to be international medical graduates and either younger than 40 years or older than 65 years, and most had small patient panels. Although joining a medical home was financially remunerative and the obligations were minimal, we hypothesize that many older physicians were near retirement and operated solo practices that were relatively isolated. The younger physicians may not have settled into a permanent practice and may have been working at walk-in clinics. Indeed, many fee-forservice physicians likely worked in walk-in clinics and may not have considered ongoing chronic disease management and prevention within their role. The gaps in quality of care that we observed in our study between patients receiving care from a medical home and those left behind were much greater than differences in quality of care previously denoted among various medical home models. ${ }^{36}$

Primary care medical home reforms in the United States are heterogeneous, with a mix of areas, where new immigrants and patients living in poverty are more likely to reside. Our findings are not surprising in the context of international studies showing that residents living in relative deprivation have worse access to primary care, ${ }^{34}$ and they highlight the persis- public and private health plans supporting different programs of primary care delivery based on common standards. Similar to medical practice in Ontario, however, transitioning to a medical home is voluntary for most practices in the United States. As we 
found in our study, a voluntary approach risks leaving behind poorer performing practices and more deprived patients. As in Ontario, the United Kingdom also has universal primary care coverage. Medical home principles, such as enhanced access to care, team-based care, and a focus on quality and safety, have been embedded in primary care practices in the United Kingdom for some time. ${ }^{37,38} \mathrm{~A}$ voluntary pay-for-performance program had widespread uptake in the United Kingdom and reduced inequalities in the quality of primary clinical care ${ }^{39}$ Still, there are some practices with lower quality-of-care scores. Similar to our findings, researchers have found that these practices are more likely to be staffed by elderly physicians, solo practices, and located in poorer neighborhoods. ${ }^{40}$

Our study has both strengths and limitations. Although our reliance on administrative data enabled us to assess care for all Ontario residents, it precluded us from assessing such aspects of care as the patient's experience, timely access, and intermediate outcomes (eg, blood pressure levels). There were important differences in patient characteristics between those attached and not attached to a medical home, and these differences may explain some of the findings despite our attempts to control for differences in our modeling. There were also differences in physician characteristics, but we chose not to control for these differences in our regression modeling. Physicians self-selected to join medical homes; we hypothesized that differences in physician characteristics were entwined with differences in care delivery between the models, and controlling for them would have put us at risk of overadjustment.

We compared differences in quality of care at a single point in time, but we also performed a longitudinal analysis to understand whether differences predated medical home reforms. Implementation of medical home reforms was heterogeneous; patients and physicians switching between different medical home models multiple times in a short period made it difficult to use a more traditional prospective cohort design. Instead, we used a look-back method of comparison that was similar to work we have done previously. ${ }^{36,41}$ Finally, we used an established methodology to match patients who were not formally enrolled to a primary care physician, but it is unclear whether patients themselves would consider that physician to be responsible for their primary care.

Even though Ontario boasts universal coverage for primary care, we found significant variation in chronic disease management and prevention based on whether patients are attached to a medical home. Some unattached patients simply need a family physician. The new Ontario government has pledged universal access to primary care, ${ }^{42}$ but the policy levers for ensur- ing such access are still unclear. Other patients who are seeing fee-for-service physicians are less likely to receive recommended care. Strategies are needed to support these fee-for-service physicians and address gaps in care. Options range from outreach facilitation to compulsory practice accreditation. At the same time, policy makers will need to address the role of walk-in clinics, weighing the benefits (access to care for acute concerns) with the harms (fragmented or absent chronic disease management and prevention). Physicians currently practicing in a medical home can address gaps in care for this underserved population by accepting unattached patients and offering support to fee-for-service physicians, such as mentorship or assistance with quality improvement activities.

Almost a decade after their introduction, medical home reforms in Ontario have left behind a large group of patients who are more likely to be poor, urban, and new immigrants and who have traditionally received lower quality care. Strategies are needed to improve care for these patients either through improved primary care attachment or improved services with their existing physician.

To read or post commentaries in response to this article, see it online at http://www.annfammed.org/content/14/6/517.

Keywords: primary health care; access to health care; health care delivery; health care disparities; health policy

Submitted December 22, 2015; submitted, revised, June 19, 2016; accepted July 6, 2016.

Funding support: This study was supported by the Institute for Clinical Evaluative Sciences, funded by annual grants from the Ontario Ministry of Health and Long-Term Care. Dr Kiran is supported as a Clinician Investigator and Dr Glazier as a Clinician Scientist by the Department of Family and Community Medicine at the University of Toronto and at St Michael's Hospital.

Disclaimer: The opinions, results, analyses, and conclusions reported in this article are those of the authors and are independent from the funding sources. No endorsement by the Institute for Clinical Evaluative Sciences or the Ontario Ministry of Health and Long-Term Care is intended or should be inferred. Parts of this material are based on data and information compiled and provided by Canadian Institute for Health Information (CIHI) and by Cancer Care Ontario (CCO). However, the analyses, conclusions, opinions and statements expressed herein are those of the authors and not necessarily those of $\mathrm{CIHI}$ or CCO. No endorsement by $\mathrm{CIHI}$ or CCO is intended or should be inferred.

Previous presentation: Oral presentation at Trillium Primary Care Research Day; June 4, 2015; Toronto, Canada.

Acknowledgments: We would like to thank Sue Schultz, Senior Epidemiologist, Institute for Clinical Evaluative Sciences, for her work on developing the algorithm to distinguish between comprehensive and noncomprehensive fee-for-service primary care physicians.

Supplementary materials: Available at http://www.AnnFamMed. org/content/14/6/517/suppl/DC1/. 


\section{References}

1. Starfield B, Shi L, Macinko J. Contribution of primary care to health systems and health. Milbank Q. 2005;83(3):457-502.

2. Bodenheimer T, Pham HH. Primary care: current problems and proposed solutions. Health Aff (Millwood). 2010;29(5):799-805.

3. Larson EB, Reid R. The patient-centered medical home movement: why now? JAMA. 2010;303(16):1644-1645.

4. Reid RJ, Fishman PA, Yu O, et al. Patient-centered medical home demonstration: a prospective, quasi-experimental, before and after evaluation. Am J Manag Care. 2009;15(9):e71-e87.

5. The College of Family Physicians of Canada. Family Practice: The Patient's Medical Home. Mississauga, ON; 2011.

6. American Academy of Family Physicians, American Academy of Pediatrics, American College of Physicians, American Osteopathic Association. Joint principles of the patient-centered medical home. http:// www.aafp.org/dam/AAFP/documents/practice_management/pcmh/ initiatives/PCMHJoint.pdf. Accessed May 5, 2015.

7. Nutting PA, Crabtree BF, Miller WL, Stange KC, Stewart E, Jaén C. Transforming physician practices to patient-centered medical homes: lessons from the national demonstration project. Health Aff (Millwood). 2011;30(3):439-445.

8. Phillips RL, Pugno PA, Saultz JW, et al. Health is primary: Family medicine for Americas health. Ann Fam Med. 2014;12(Suppl 1):S1-S12.

9. Jackson GL, Powers BJ, Chatterjee R, et al. The patient-centered medical home: a systematic review. Ann Intern Med. 2013;158(3):169-178.

10. Markovitz AR, Alexander JA, Lantz PM, Paustian ML. Patientcentered medical home implementation and use of preventive services: the role of practice socioeconomic context. JAMA Intern Med. 2015;175(4):598-606.

11. Nelson KM, Helfrich C, Sun $\mathrm{H}$, et al. Implementation of the patientcentered medical home in the Veterans Health Administration: associations with patient satisfaction, quality of care, staff burnout, and hospital and emergency department use. JAMA Intern Med. 2014; 174(8):1350-1358.

12. Phillips RL, Han M, Petterson SM, Makaroff LA, Liaw WR. Cost, utilization, and quality of care: an evaluation of illinois medicaid primary care case management program. Ann Fam Med. 2014;12(5):408-417.

13. David G, Gunnarsson C, Saynisch PA, Chawla R, Nigam S. Do patientcentered medical homes reduce emergency department visits? Health Serv Res. 2015;50(2):418-439.

14. Hutchison B, Glazier R. Ontarios primary care reforms have transformed the local care landscape, but a plan is needed for ongoing improvement. Health Aff (Millwood). 2013;32(4):695-703.

15. Henry DA, Schultz SE, Glazier RH, Bhatia RS, Dhalla IA, Laupacis A. Payments to Ontario Physicians from Ministry of Health and Long-Term Care Sources, 1992/93 to 2009/10; ICES Investigative Report. Toronto, Canada: Institute for Clinical Evaluative Sciences; 2012.

16. Kiran T, Victor JC, Kopp A, Shah BR, Glazier RH. The relationship between primary care models and processes of diabetes care in Ontario. Can J Diabetes. 2014;38(3):172-178.

17. Liddy C, Singh J, Hogg W, Dahrouge S, Taljaard M. Comparison of primary care models in the prevention of cardiovascular disease - a cross sectional study. BMC Fam Pract. 2011;12(1):114.

18. Hux JE, Ivis F, Flintoft V, Bica A. Diabetes in Ontario: determination of prevalence and incidence using a validated administrative data algorithm. Diabetes Care. 2002;25(3):512-516.

19. Canadian Diabetes Association Clinical Practice Guidelines Expert Committee. Canadian Diabetes Association 2008 clinical practice guidelines for the prevention and management of diabetes in Canada. Canadian Journal of Diabetes. 2008;32(1):S1-S201.

20. Kiran T, Wilton AS, Moineddin R, Paszat L, Glazier RH. Effect of payment incentives on cancer screening in Ontario primary care. Ann Fam Med. 2014;12(4):317-323.
21. Kralj B. Measuring "rurality" for purposes of health-care planning: an empirical measure for Ontario. Toronto: Ontario Medical Review, 2000.

22. The Johns Hopkins ACG System. http://www.acg.jhsph.org/.

23. Alter DA, Naylor CD, Austin P, Tu JV. Effects of socioeconomic status on access to invasive cardiac procedures and on mortality after acute myocardial infarction. N Engl J Med. 1999;341(18):1359-1367.

24. Gershon AS, Wang C, Guan J, Vasilevska-Ristovska J, Cicutto L, To $\mathrm{T}$. Identifying individuals with physcian diagnosed COPD in health administrative databases. COPD. 2009;6(5):388-394.

25. Gershon AS, Wang C, Guan J, Vasilevska-Ristovska J, Cicutto L, To T. Identifying patients with physician-diagnosed asthma in health administrative databases. Can Respir J. 2009;16(6):183-188.

26. Schultz SE, Rothwell DM, Chen Z, Tu K. Identifying cases of congestive heart failure from administrative data: a validation study using primary care patient records. Chronic Dis Inj Can. 2013;33(3).

27. Steele LS, Glazier RH, Lin E, Evans M. Using administrative data to measure ambulatory mental health service provision in primary care. Med Care. 2004;42(10):960-965.

28. Tu K, Campbell NRC, Chen Z-L, Cauch-Dudek KJ, McAlister FA. Accuracy of administrative databases in identifying patients with hypertension. Open Med. 2007;1(1):e18-e26.

29. McNutt L-A, Wu C, Xue X, Hafner JP. Estimating the relative risk in cohort studies and clinical trials of common outcomes. Am J Epidemiol. 2003;157(10):940-943.

30. Hubbard AE, Ahern J, Fleischer NL, et al. To GEE or not to GEE: comparing population average and mixed models for estimating the associations between neighborhood risk factors and health. Epidemiology. 2010;21(4):467-474.

31. Safarov A, Grava-Gubins I, Eriksson J. Access to primary care in Canada: national physician survey perspective. North Amer Primary Care Research Group Annual Conf; December 1-5, 2012; New Orleans, LA.

32. Ontario Ministry of Health and Long Term Care. Health care options near you. http://www.ontario.ca/locations/health/.

33. Glazier RHZB, Rayner J. Comparison of Primary Care Models in Ontario by Demographics, Case Mix and Emergency Department Use, 2008/09 to 2009/10; ICES Investigative Report. Toronto, Canada: Institute for Clinical Evaluative Sciences; 2012.

34. Exworthy M, Bindman A, Davies $H$, Washington AE. Evidence into policy and practice? Measuring the progress of U.S. and U.K. policies to tackle disparities and inequalities in U.S. and U.K. health and health care. Milbank Q. 2006;84(1):75.

35. Hart JT. The inverse care law. Lancet. 1971;1(7696):405-412.

36. Kiran T, Kopp A, Moineddin R, Glazier RH. Longitudinal evaluation of physician payment reform and team-based care for chronic disease management and prevention. CMAJ. 2015.

37. Marshall M. A precious jewel: the role of general practice in the English NHS. N Engl J Med. 2015;372(10):893-897.

38. Roland M. The future of primary care: lessons from the U.K. N Engl J Med. 2008;359(20):2087-2092.

39. Doran T, Fullwood C, Kontopantelis E, Reeves D. Effect of financial incentives on inequalities in the delivery of primary clinical care in England: analysis of clinical activity indicators for the quality and outcomes framework. Lancet. 2008;372(9640):728-736.

40. Ashworth M, Schofield P, Seed P, Durbaba S, Kordowicz M, Jones R. Identifying poorly performing general practices in England: a longitudinal study using data from the quality and outcomes framework. J Health Serv Res Policy. 2011;16(1):21-27.

41. Kiran T, Victor JC, Kopp A, Shah BR, Glazier RH. The relationship between financial incentives and quality of diabetes care in Ontario, Canada. Diabetes Care. 2012; 35(5):1038-1046.

42. Miller A. Wynne promises 24-7 healthcare by 2018 if Liberals elected. CTV News. May 30, 2014. http://www.ctvnews.ca/politics/ ontario-election-2014/wynne-promises-24-7-healthcare-by-2018-ifliberals-elected-1.1845902. Accessed Nov 13, 2015. 